\title{
Democratizing digital learning: theorizing the fully online learning community model
}

Open Access

Todd J. B. Blayone ${ }^{1 *}$, Roland vanOostveen ${ }^{1}$, Wendy Barber ${ }^{1}$, Maurice DiGiuseppe ${ }^{1}$ and Elizabeth Childs ${ }^{2}$

\author{
* Correspondence: \\ todd.blayone@uoit.ca \\ ${ }^{1}$ University of Ontario Institute of \\ Technology, Oshawa, Canada \\ Full list of author information is \\ available at the end of the article
}

\begin{abstract}
The integration of digital technologies at institutions of higher education are profoundly influencing formal learning on a global scale. Social-constructivist models of fully online learning are well-positioned to address the demands of government, and economic and social-development organizations for civically-engaged individuals with strong problem-solving, critical-thinking and collaboration competencies. With an established record of performance at the University of Ontario Institute of Technology (UOIT), Canada, the Fully Online Learning Community (FOLC) is one such model.

This paper theorizes FOLC as a response to several problematics, including (a) the aforementioned demand for greater educational focus on higher-order competency development, (b) the deficiencies of distance education and MOOCs as learning models, and (c) a quest for new learning models that strengthen deliberation skills and deepen democratic experience. As a divergent fork of the Community of Inquiry model, FOLC describes collaborative learning as a symbiosis of social and cognitive interactions amplified through effective use of synchronous and asynchronous digital affordances. Furthermore, it models democratized learning communities that reduce transactional distance between learners and educators, incorporates authentic assessment, and encourages negotiated technology affordances and cognitive outcomes while distributing responsibility for constructive criticality.

Having positioned FOLC conceptually, and addressed current limitations, a research agenda for extending its empirical foundations, and leveraging UOIT's EILAB affordances, is presented. The underlying argument is that self-regulating and transformative learning communities can be established and sustained in fully online environments, and that such communities (a) produce a diversity of beneficial learning outcomes, and (b) deepen the democratic functioning of learners and their social contexts.

Keywords: Online learning, E-learning, Collaborative learning, Fully online learning community model, Problem-based learning, Learning and democracy, Social constructivist learning, Community of inquiry, Digital learning model
\end{abstract}

\section{Introduction}

There were more than 40 million higher-education students in the world taking one or more of their classes online in 2013 (Atkins, 2013). Allen and Seaman (2016) indicate that over $28 \%$ of students enrolled in degree-granting institutions in the U.S. took at least one online course in 2014. In Canada, over 20,000 online courses are available through colleges and universities in the province of Ontario alone (Contact North, 2016). Looking beyond these well-cited numbers, digital learning represents a diverse phenomenon shaped by context, social values, learning models and level of digital integration (Aparicio, Bacao,

(c) The Author(s). 2017 Open Access This article is distributed under the terms of the Creative Commons Attribution 4.0 International License (http://creativecommons.org/licenses/by/4.0/), which permits unrestricted use, distribution, and reproduction in any medium, provided you give appropriate credit to the original author(s) and the source, provide a link to the Creative Commons license, and indicate if changes were made. 
\& Oliveira, 2016; Siemens, Gašević, \& Dawson, 2015). For example, blended or hybrid models ask participants to complete some tasks using online tools in addition to attending in-class lectures or tutorials. Fully online programs do not require participants to be on campus for course-related purposes, except by choice to use extra-curricular resources. In these programs, individuals engage in learning activities in a shared "digital space" using a mix of synchronous and asynchronous affordances. Among fully online programs and models, some focus on supporting highly individualized modes of learning with optional forms of cooperation (Dalsgaard \& Paulsen, 2009; Paulsen, 2003, 2008). Others emphasize transactional learning in which social interaction and collaboration is essential for reducing confirmation bias and building socially meaningful knowledge (Garrison, 2016).

The Fully Online Learning Community (FOLC) model (vanOostveen et al., 2016) was developed in the Faculty of Education at the University of Ontario Institute of Technology (UOIT), a mid-sized, Canadian technology-oriented university. This transactional model was conceived as an offshoot of the Community of Inquiry (CoI) model (Garrison, 2011; Garrison, Anderson, \& Archer, 2000). However, as described below, through extensive praxis and ongoing empirical study, FOLC is evolving conceptually as a distinct alternative to the CoI by foregrounding democratized and emancipatory learning processes that are adaptable to the socio-cultural context of institutions and learners.

\section{Context}

FOLC responds to four problems related to the transformation of higher education in an increasingly globalized and digitalized knowledge society. Firstly, it responds to the limitations of distance learning and MOOCs (e.g., student isolation, low completion rates, etc.), and their accompanying assumptions about learning as the "delivery" of expert information to the masses (Miller, 2014). Challenging the tacit epistemology of distance learning, FOLC embraces the constructivist notion that all efforts to understand "reality," including virtual reality, involves the social creation of knowledge and not just individual "ingestion" of information (Johnson \& Liber, 2008).

Secondly, FOLC responds to the call for greater development of 21st century competencies desired by influential organizations such as the World Economic Forum (2016) and the Conference Board of Canada (2016). These competencies are characterized as (a) traversal, or foundational to the development of other key competencies across domains; (b) multidimensional, including knowledge, skills and attitudes; and (c) related to higher-order abilities that support complex problem-solving (Voogt \& Roblin, 2012), and collaborative thinking (Garrison, 2016).

Thirdly, FOLC's activity, control, and community orientations respond to the needs of transformative and emancipatory learning as conceptualized by Human Rights Education (Tibbitts, 2005; Tibbitts \& Kirchschlaeger, 2010) and Social Justice Education (Grant \& Gibson, 2013). Several specific conditions fostering transformative learning identified by Taylor $(2007,2008,2016)$, and strongly supported by FOLC-based learning environments, include:

- An environment that promotes a sense of safety, openness, and trust, encouraging the sharing of emotions as preparation for critical reflection.

- Activities that facilitate the exploration of divergent perspectives, problem solving, and critical thinking. 
- A community that promotes each member's sense of autonomy, engagement, and collaboration.

- The use of feedback, self-assessment, and self-dialogue that are used to assist the process of transformative learning.

Fourthly and finally, FOLC responds to requests from some international partners for new models of learning aligned with democratic and socio-economic reforms (Hellwig \& Lipenkowa, 2007; Kutsyuruba, 2011; Kutsyuruba \& Kovalchuk, 2015). In 2016, FOLC served as a transformative educational model for a pilot project in Ukraine (Mykhailenko, Blayone, \& VanOostveen, 2016). It was selected because collaborative and participatory learning is associated with higher levels of self-efficacy and social engagement (Tibbitts \& Kirchschlaeger, 2010).

\section{Origins}

FOLC originated as an offshoot of the CoI model, and as such, builds upon shared foundations. Most importantly, FOLC, like the CoI, is a reduced social-constructivist learning model addressing those processes considered most central to deep learning. These processes are construed as interactions or transactions (Garrison et al., 2000) categorized by several presences. According to Richardson et al. (2012), the term "presence" highlights the essential quality of learning transactions as shared functions rather than exchanges involving specific actors (e.g., teacher, student), and it suggests a community-orientation in which participants share responsibility and control of the experience. This community orientation to inquiry, well-articulated by Lipman (2003), sets FOLC and the CoI apart from generic e-learning models like that of Anderson (2004), which seeks to include non-constructivist distance education. It also places FOLC in tension with cooperative-learning models that emphasize individual freedom as a core value (Dalsgaard \& Paulsen, 2009; Paulsen, 2008) because mandatory synchronous collaboration may impinge upon individual freedom.

Such tension springs from the philosophical foundations FOLC shares with the CoI, of which Dewey's fusion of the personal and social dimensions of learning is central (Dewey, 1897). This fusion is well-developed in the work of Garrison (2011, 2016), who, as an expositor of Dewey, explains that learning becomes meaningful when it builds directly on the experience and culture of an individual learner, and is encountered through personal reflection. Moreover, learning becomes worthwhile when it is expressed, submitted to processes of collaborative critical discourse (an essential aspect of personal cognitive development), and survives as a knowledge artifact deemed useful by a CoI (Fig. 1).

\section{Conceptual dimensions}

As an offshoot of the CoI, FOLC diverges in several ways. Firstly, although CoI theorizes a Social Presence (SP), Cognitive Presence (CP), and Teaching Presence (TP), FOLC incorporates SP and CP only. It subsumes TP fully within the other presences. This move, rooted in a democratized approach to learning, places much greater emphasis on the community and learner empowerment. Secondly, FOLC introduces the "digital space" as a dynamic, negotiated, contextual construct with potential to extend the scope and amplify SP and CP. Thirdly, FOLC is conceptually inclusive, 


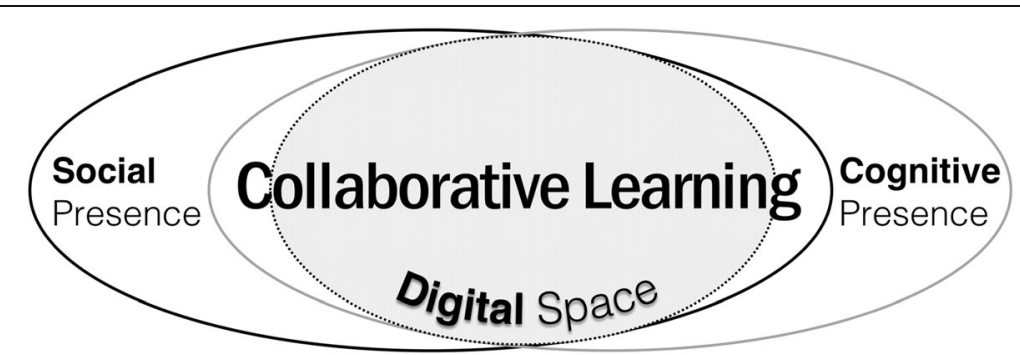

Fig. 1 The Fully Online Learning Community Model. The synergistic dimensions of the Fully Online Learning Community (FOLC) model are conceptualized as Social Presence (SP) and Cognitive Presence (CP) occurring primarily within a Digital Space comprised of community-selected, asynchronous and synchronous affordances. Successful Collaborative Learning occurs at the intersection of these dimensions as the learners develop their sense of community and requisite digital competencies are applied to support critical inquiry. Recognizing that not all social and cognitive interactions are digitally mediated, even in fully online courses/programs, FOLC may be adapted to hybrid-learning environments by strategically resizing/repositioning the Digital Space in relation to $\mathrm{SP}$ and $\mathrm{CP}$

incorporating several subsidiary models, which address additional layers of the learning experience (e.g., learning activities and goals, digital devices and competencies, responsibility and control, community formation and assessment).

To date, in the originating context of UOIT, the following sub-models have been used to enrich and adapt FOLC in specific contexts of practice and research.

- Problem and inquiry-based learning (Savin-Baden, 2000, 2007).

- General Technology Competency and Use (Desjardins, 2005; Desjardins et al., 2015; Desjardins, Lacasse, \& Belair, 2001; Desjardins \& vanOostveen, 2015).

- Teaching Learning Paradigm model (Coomey \& Stephenson, 2001; Layne \& Ice, 2014)

- Community of Practice (Lave \& Wenger, 1991; Wenger, 1998; Wenger \& Snyder, 2000)

- Transactional Distance (Moore, 1993)

- Authentic Assessment (Herrington \& Herrington, 1998; Herrington, Reeves, \& Oliver, 2006)

- Dimensions of culture (Hofstede, 1986, 2001, 2011; Minkov, 2012)

Incorporation of culture-related sub-models is in its infancy. Although the subdomain of online learning and cultural analysis is producing a significant amount of empirical literature (Edmundson, 2007; Goodfellow \& Lamy, 2009; Gunawardena, 2014; Gunawardena, Wilson, \& Nolla, 2003; Palalas, Berezin, Gunawardena, \& Kramer, 2015), there is much debate over models and methods, particularly in relation to incorporating cross-cultural analysis with homogenous versus multicultural groupings. To date, FOLC researchers have explored cultural values of Ukrainian university students and professors using the model of Hofstede (2001) and the Cultural Values Scale (Yoo, Donthu, \& Lenartowicz, 2011) in the context of a fully online pilot course facilitated in Canada.

\section{Social presence}

Initially, COI researchers, building on the literature of Computer Mediated Communication (CMC), defined SP as "the ability of learners to project themselves socially and emotionally in a community of inquiry" (Rourke, Anderson, Garrison, \& Archer, 1999) or as 
"real people" (with their full personality) through digital technology (Garrison et al., 2000). In this early research, SP was studied empirically through discourse analysis of asynchronous discussion transcripts. This methodology demonstrated the ability of text-based conferencing to support highly affective interpersonal interactions, a sense of immediacy, and group cohesiveness (Rourke et al., 1999). Findings from a decade of empirical CoI research triggered a reorientation of SP as "the ability of participants to identify with the group or course of study, communicate purposefully in a trusting environment, and develop personal and affective relationships progressively by way of projecting their individual personalities" (Garrison, 2011, p. 34). This development shifted emphasis from emotional involvement and interpersonal relationships, for their own sake, to their ability to foster learning communities driven by a shared educational purpose.

FOLC is well-aligned with the Col's current conceptualization of SP. At the same time, the issue of whether learners in an online environment are perceived as "real"-based on the work of Gunawardena (1995) - continues to inform FOLC's conceptualization and empirical exploration of SP because this perception is thought to influence the authenticity of relationships in a learning community, and consequently, the quality of cognitive interaction (vanOostveen, Childs, Clarkson, \& Flynn, 2015).

\section{Cognitive presence}

The CoI conceptualizes and operationalizes CP using Dewey's Practical Inquiry model (Dewey, 1933). This four-phase procedural model, considered a generalization of scientific method, begins with a triggering event, and subsequently moves through phases of exploration, integration, and resolution (Garrison, 2016). Exploration often involves individual research while integration incorporates collaborative analysis, evaluation, negotiation, and synthesis, leading to some form of resolution. The key idea is that knowledge constructed in the mind becomes a contestable external artifact, thus minimizing confirmation bias (Garrison, 2016). This process of knowledge externalization finds a conceptual analog in Popper's cosmology in which "World II" objects (internal, individualistic schema) are translated into "World III" (public thought) products, in order to facilitate scientific analysis, and processes of refutation and defence (Popper, 1978).

FOLC recognizes the merits of Dewey's model, particularly the focus on rigorous inquiry, and the responsibility of every learner to transform potentially useful ideas into socially contestable knowledge. However, FOLC explores somewhat more flexible inquiry models to operationalize CP. To date, FOLC learning communities have synthesized and incorporated (a) a Science \& Technology Education framework built on a social constructivist perspective (Bencze, 2008), and (b) Problem-based Learning that emphasizes learner-controlled analysis and interpretation of contexts (problem creation) rather than teacher-defined problems or triggering questions. Therefore, in place of Dewey's practical inquiry model, FOLC communities define and explore proble$\mathrm{ms}$ - through consideration of the difference between current and desired situations in relation to knowledge, resources, roles/perspectives, and obstacles-and collaborative "solutions," most often in the form of publically contestable knowledge artifacts.

Finally, FOLC emphasizes the synergistic relationship between SP and CP, particularly when collaborative learning is supported through online, synchronous, videoconferencing environments. As Armellini and De Stefani (2015) observe, "the social 
element permeates most layers of cognitive presence," (p. 9) and SP "operate[s] well as a stand-alone construct (p. 11)." This description represents the ideal dynamics of a social constructivist learning community.

\section{Digital space}

CoI views digital technologies and the competencies required to use them effectively as extraneous to the core model. It was thought that to include these elements would make the CoI model unreasonably complex (Garrison, 2011, p. 28). FOLC resists this reduction, conceptualizing the digital context as a powerful mediator and potential amplifier of SP and CP within fully online environments. Using the General Technology Competency and Use framework (Desjardins, 2005), as a sub-model, FOLC recognizes four fundamental dimensions of human-computer-human interaction (technical, informational, social, and epistemological/computational) and their accompanying competencies as prerequisite layers supporting SP, CP, and collaborative learning.

Additionally, FOLC offers well-established practices for the selection and use of digital affordances to foster fully online community learning. Within a FOLC-based program, like the Educational Studies and Digital Technology (ESDT) undergraduate degree program at UOIT, the professional educator seeds the digital space by posting videos to YouTube and providing facilitated tutorial sessions in a browser-based, audiovideo conferencing suite. Subsequently, when working collaboratively in small groups, Open Educational Resources (OER) and other web-based applications are chosen by the learners in accordance with two specific principles: (a) resources used must be shareable, and (b) the URL for the site(s) must be provided to everyone in the learning community. The tools and applications selected facilitate both synchronous and asynchronous communication, allowing for greater clarity and effectiveness of interaction than can be achieved using asynchronous technologies alone (Trevino, Lengel, \& Daft, 1987; Rockinson-Szapkiw \& Wendt, 2015).

In particular, use of a browser-based audio-video conferencing tool, in which each individual is represented by a "real time" (web-cam) image, and by audio interactions through a microphone headset, provides a strong semblance of face-to-face interactions which allow participants to present themselves as "real people." The use of visual cues such as facial expressions and body language, audio cues from direct speech, and the incorporation of text chat, foster community and collaborative learning (Hrastinski, 2008; RockinsonSzapkiw \& Wendt, 2015).

FOLC's digital space is an oftentimes unpredictable context for online learning. It is not a neutral space, but one purposefully created by learners whose chosen applications and platforms significantly influence interactions. Even social-media applications like Facebook may be selected as a learning platforms despite our experience that the discussion functionality limits rigorous collaborative inquiry, and places limits on CP. In a FOLC environment, exploring such limits is a matter of discussion and debate rather than a situation to be avoided. Kearney, Schuck, Burden, and Aubusson (2012) emphasize that it is important to consider "what a pedagogical framework for m-learning may look like from a socio-cultural perspective" (2nd paragraph). This perspective emphasizes reciprocity - that learning is affected and modified by the tools used for learning, and at the same time, learning tools are modified by the ways in which they are used for learning (Fig. 2). 


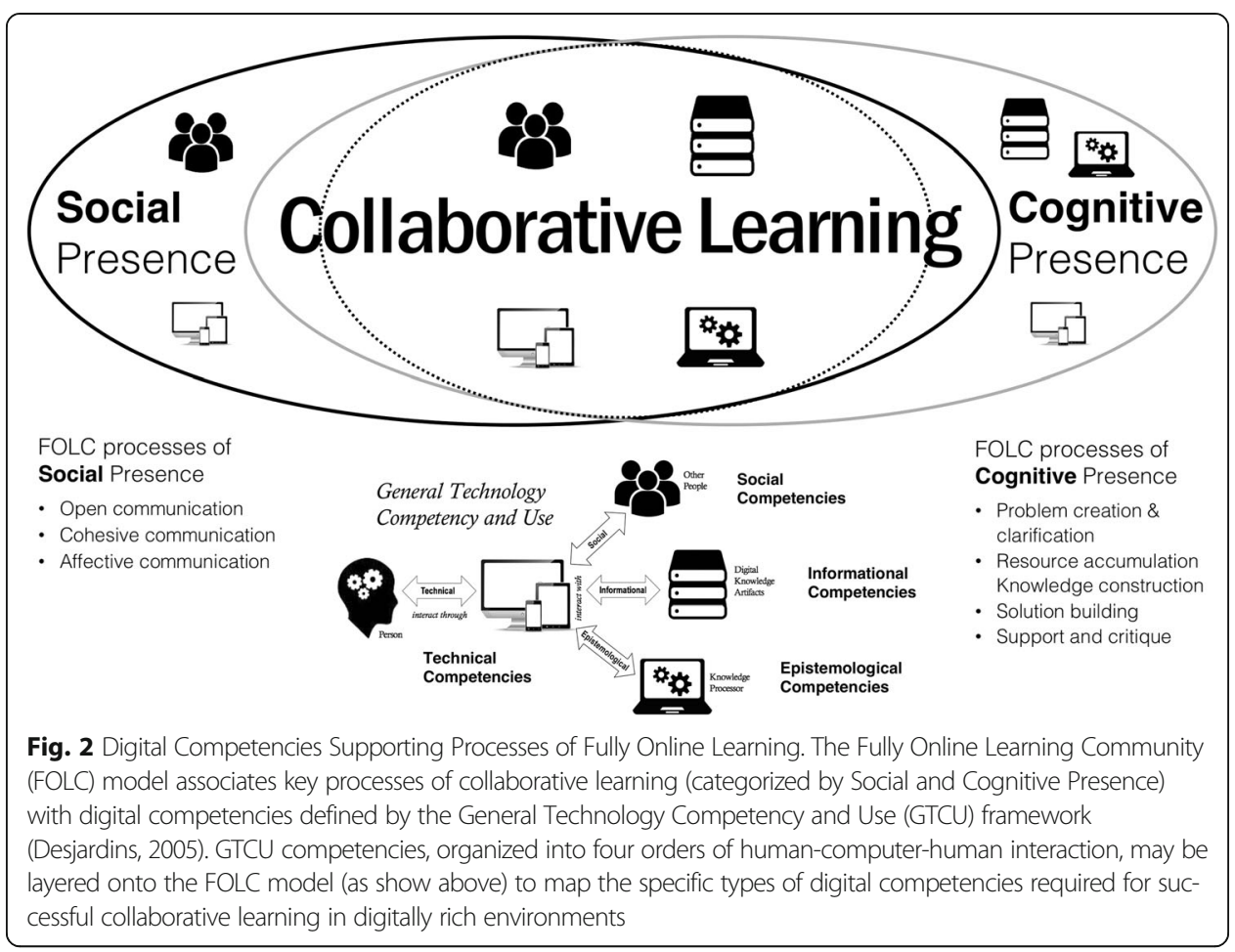

\section{Democratized learning}

\section{A boundary concept}

"Democratized learning" is a loose, boundary construct with scattered presence in the literature (Jones \& Graham, 2015; Rubin, 2007). Löwy (1990) notes that such constructs often emerge through cross-disciplinary inquiry, and can facilitate innovations in research, even though they may remain ill-defined throughout their scientific life span. In the context of international FOLC research collaborations, four "boundary markers" have emerged to describe democratized learning:

1. It addresses processes of learning, not learning or teaching about democracy.

2. It functions as a response to a paradox-namely, that education is considered vital for the development of democracy and human rights, yet, at the micro-level of learning, education tends to be authoritarian-even in so-called developed democracies. As Bivens and Taylor (2008) observe, traditional learning is:

premised on the assumption that students are empty vessels that need to be filled up with information. The flow of information is one way, from teacher to students. The teacher controls the...experience, while the role of the student is to receive knowledge passively (p. 282).

Levin (2000) offers a similar assessment in relation to educational reform, suggesting that it represents

a history of doing things to other people, supposedly for their own good. Each level in the hierarchy of education believes it knows best what those at lower levels need to do, and has little shyness about telling them or, just as often, forcing them (p. 155). 
3. It can be situated within the broader academic discourse of deepening democracy, as opposed to the triumphant discourse on the ascendency of democratic nation states. As Gaventa (2006) notes, the discourse of "deepening democracy" challenges the reduction of citizens to consumers who express freedoms through market choices rather than through critical deliberation and emancipatory praxis.

4. It gains strength through digital technologies, which are construed as powerful amplifiers of human empowerment and learning, when inequalities of access and competency are addressed.

Within the space bounded by these markers, key themes emerge in relation to FOLC educational environments, including: (a) collective identity and responsibility, (b) freedom and flexibility, (c) authenticity, and (d) community and criticality. These themes, as described below, are not so much defining characteristics as family resemblances. That is, no single set of themes is likely to characterize any context of democratized learning. Indeed, some themes, such as freedom and community, may stand in tension, a phenomenon well established in the history of human rights discourse (Grant \& Gibson, 2013).

\section{Collective identity and responsibility}

In a democratized learning environment, there are significant shifts in power and control. Given that most adults have experienced traditional pedagogical techniques such as lectures, teacher-centred lessons and grade-based assessments, bringing a real sense of democracy to the digital environment challenges previous notions of what learning online can or should be. This requires adopting a shared collective identity, as learners become committed to rigorous forms of problem-solving and inquiry that is valued by the community. FOLC pursues the development of learning environments that (a) build interpersonal relationships; (b) promote distributed responsibility for refining knowledge through challenging feedback that triggers cognitive dissonance; and (c) encourage divergent thinking. The power structure where a lecturer directs the class has been replaced with a collaborative approach where transactional distance is decreased.

Problem-based Learning, authentic assessment, adult learning, and meaning-making provide powerful pathways to community development. Taken together, they transform the nature of learning, the instructors' role, and the learners' evolution towards selfdirected learning. Learners begin to exhibit greater competence and confidence in using open source digital resources, they require less direction from others, and they become more engaged inquirers.

\section{Freedom and flexibility}

As individuals co-design their collaborative learning environment, there is an emphasis on personalizing the learning environment within the community. In this way, adults share both structure and control of the digital space, respecting diverse personal learning needs, and working together to improve performance. Individuals bring a variety of digital tools and skills to the FOLC, and by making this knowledge and skill available to everyone, the community members can improve group and individual performance, as well as abilities to solve problems by sharing the differing resources and backgrounds that each individual offers to the group. Personalizing the learning environment also 
can allow for a sense of safety and trust from which critical feedback is welcomed and seen as a tool for challenging and improving thinking. Johnson and Liber (2008) discuss the importance of a learning environment which provides a "learner-driven model of education, where the traditional provider-centric role of institutions is challenged," and they ascribe this importance to the "rise in personal technology, particularly the emerging situation where the power of personal technology is often seen to outstrip the technological provision of institutions" (p. 3).

Given that institutions are increasingly adopting a Bring your Own Device (BYOD) policy, more responsibility is placed on the learner and less on the institution to provide "training" in specific digital tools. This mimics what happens in real world situations, where individuals learn what they need to know "just in time" by, say, using the Internet or other digital tools.

\section{Authenticity (of activities and assessment)}

The FOLC learning environment requires that individuals take ownership of their learning and that they contribute to the group as well as engage with the chosen tasks. Consequently, it is imperative that the learning activities are perceived as authentic, based in the real world, and relevant to the learners. Herrington and Parker (2013) state that a pedagogical framework and learning environment within which authentic learning activities exist possess the following nine basic elements: (1) an authentic context, (2) authentic tasks and activities, (3) access to expert performances, (4) multiple perspectives, (5) collaboration, (6) reflection, (7) articulation, (8) coaching, and (9) authentic assessment (p. 610). Including students in the design and choice of learning activities allows the opportunity for autonomy, independence, risk taking, and collaboration with others. If students do not see their learning as having real-world integrity, they tend to become disengaged. This is of concern in online environments, where students might otherwise become disinterested and feel isolated.

Flint and Johnson (2011) concur, and indicate that "if students do not see the relevance of a task, they get frustrated and annoyed" (p. 74). Thus, authentic learning activities are those that include students in selecting the technical tools they wish to employ and learn with; the ideas they want to discover; and the problems that are relevant to their realworld experiences. Chen, Wang, Yang, Lu, and Chang (2013) refer to a "digital playground" (p. 172), and they state that ideal and interactive learning activities have ten basic design elements, including, "real world relevance, ill-defined problems, sustained investigation, multiple perspectives, collaboration, reflection, interdisciplinary perspectives, integrated assessment, polished products and multiple interpretations" (p. 173). These elements align well with Savin-Baden's (2007) criteria for Problem-based Learning and the role of ill-structured problems in ideal learning situations.

With respect to assessment, traditional practices include diagnostic, formative, and summative, and they are usually based on the concept of assessing a certain quantity of content knowledge or set of learning outcomes. FOLC suggests that in a democratized learning environment, our approaches to assessment need to change. Although we may continue to use some diagnostic, formative, and summative forms of assessment, new approaches to democratic assessment practices require instructors to use more integrative assessment, and to include assessment as a seamless and widely distributed part of the learning process. When engaging in FOLC-structured environments, learners and 
instructors/facilitators not only co-design the digital learning space, but they should also be co-designing the means, timing, methods, and types of assessment that most accurately indicate learner success. As McCarthy (2013) states, "one of the distinctive characteristics of the millennial generation is the desire for continuous feedback and rewards for achievement, and they continue to seek feedback both in their studies and the workplace" (p. 81). McCarthy (2013) further indicates that instructors need to "encourage student[s] to take ownership of their own learning and to use each assignment to develop and grow" (p. 82). Thus, the design of assignments in learning modules requires learner input to have relevance and meaning. Co-developing assignments and success criteria address the principles for authentic assessment as discussed in Herrington and Herrington (1998) and the notion that instructors should consider "situated learning and the social context of assessment" (p. 306).

Furthermore, in terms of designing assignments and learning tasks, McCarthy (2013) further states:

Our assessments are designed not only to assess students' learning but to encourage student learning, in other words assessments are not only intended to assess the standard which students have reached but form an integral part of the curriculum and learning experience. We do this by creating assignments which are relevant both to the course content and to the workplace. We incorporate reflection in each assignment to ensure that students not only engage critically with the theory but understand how it applies in their own practice, (p. 83).

Thus, democratized learning environments need to be fundamentally based on key principles of adult learning (Mezirow, 1991; Knowles, Holton et al., 2005).

\section{Community and criticality}

"Community" is frequently encountered in the online-learning literature, but its meaning requires unraveling. Veletsianos (2016) distinguishes between "groups," "networks," and "communities," arguing that communities are made distinct by their focus on commitment, coherence, and continuity. Jézégou (2010) argued that the CoI lacked sufficient theorization regarding its community construct. Garrison (2013) responded partly through the work of Rovai (2002a, 2002b), who distinguished between weak and strong communities. Weak communities are those where members exhibit low levels of interaction and trust, and high levels of competition and divergent goals. Strong communities-what FOLC would consider an ideal-form where participants feel connected to each other, communication reduces psychological and social distance, interests are shared, and members trust and help each other.

Garrison (2013) introduces a caveat to this perspective by claiming that strong communities must build upon strong pedagogic leadership, aimed at aligning social and cognitive activities with higher-level cognitive outcomes (e.g., synthesis and resolution). Operationalized as Teaching Presence (TP), the CoI ideal is to treat such directive leadership as a community function rather than a professional role. However, in practice, $\mathrm{CoI}$ fails to challenge the institutionalization of hierarchy within learning communities. Indeed, CoI research appears less concerned with authoritarian leadership than a failure to complete Dewey's full circle of inquiry. That is, it is feared that too much social 
closeness and group safety, in the absence of directive instruction-an operational category of TP (Garrison, 2011)-could thwart criticality and encourage "groupthink" (Garrison, 2016).

FOLC takes seriously a concern for criticality, and it views recurring processes of constructive feedback among all learners (encouraged by professional educators and fostered through collaborative discourse and effective use of digital affordances) as a key characteristic of inquiring communities. However, FOLC is careful to avoid the ever-present colonial impulse, built into traditional education, that deep and meaningful learning requires directive leaders to enforce convergence and offer "correct" resolutions to problems. With professional educators envisioned as empowering, servant leaders (Parris \& Peachey, 2013), and with the goal of reducing transactional distance (Moore, 1993) between professional educators and students, FOLC aligns itself with Rovai's (2002a, 2002b) definition of a strong community, with caveats.

Further, FOLC offers a simple and flexible description of an ideal learning community, relying on the Community of Practice (CoP) as a sub-model. A community of learners modelled as a CoP, (a) represents a joint enterprise understood and continually renegotiated by its members, (b) fosters relationships of mutual engagement, and (c) establishes a shared repertoire of resources that members enthusiastically share (Wenger, 1998). This minimalist description of a learning community provides a foundation on which democratized learning might flourish.

\section{Limitations}

Like other transactional learning models (Garrison, Anderson \& Archer, 2000), FOLC offers a prescriptive or idealized perspective. In practice, the degree to which any online community, consisting of professional educators and student learners-all shaped by institutional and socio-cultural contexts-are willing (or able) to transcend traditional roles, expectations, and behaviours, particularly in relation to power and responsibility for learning, is a question requiring careful empirical study. An immediate problem is that FOLC researchers have not yet offered a full apparatus or methodology for analyzing types of interactions and accompanying dynamics of power in a given FOLC learning context-although work has begun (vanOostveen, et al., 2015). In this respect, CoI research is well advanced in wrestling with methodological issues, and some of these findings will do doubt inform ongoing operationalization and empirical development of FOLC (Garrison, Cleveland-Innes, Koole, \& Kappelman, 2006; Rourke \& Anderson, 2004; Rourke, Anderson, Garrison, \& Archer, 2001).

A related challenge for FOLC is that by taking the "extreme" measure (Beetham \& Sharpe, 2007) of not representing teaching (and directive communication) in the core model, there is no way to "see" non-democratic discourse and activities of professional instructors without moving outside the current model. One solution is to leverage an external sub-model to identify dynamics that may strain against the ideal. Recent operationalization and analysis of democratic deliberation, defined as facets of context, discourse, and participant behaviour, and drawing on the theory of Habermas (Ewert, 1991), shows promise (Coppedge, Lindberg, Skaaning, \& Teorell, 2016; Halpern \& Gibbs, 2013; Knobloch, Gastil, Reedy, \& Cramer Walsh, 2013). Additionally, activity theory presents a methodology for "zooming out the camera" in a learning context to consider dimensions of power and conflict related to several contextual variables (e.g., technology, rules, 
organizational culture, etc.) and their influence on actor positioning, identity perceptions and, behavioural choices (Morgan, 2011).

\section{Research agenda}

Conceptualization of FOLC both serves, and is served by, several streams of collaborative, empirical research. Past research, focused on fully online learning, addressed: (a) digital competencies required by teachers and students to engage successfully in the "digital space" (Desjardins \& vanOostveen, 2015; vanOostveen, Muirhead, \& Goodman, 2011), (b) learning-object design, and the optimization of affordances for Problembased Learning (PBL) (vanOostveen et al., 2010; Desjardins \& vanOostveen, 2008a; Desjardins \& vanOostveen, 2008b), and (c) social presence and community development in a web-conferencing platform (vanOostveen et al., 2015).

Current research is rapidly extending these trajectories. Moving beyond digitalcompetency research based on self-reports, FOLC's digital space is being explored through analysis of real-time performance. At the time of writing, almost 40 individual performance sessions, using a variety of mobile devices and learning-activity designs, have been captured using multi-perspectival, digital-recording techniques supported by the state-of-the-art EILAB observatory. Additionally, small-group activity sessions, in a web-conferencing environment are being digitally recorded to explore the subtle dynamics of (a) social presence (e.g., as communicated through facial expressions, body language, and words), and (b) collaboration in fully-online spaces (e.g., negotiation of affordances and roles). Analysis of these data streams, using FaceReader and The Observer XT (Noldus Information Technology, 2016) are facilitating deep exploration of digital-learning processes that extend previous observational research (Eshet-Alkalai \& Amichai-Hamburger, 2004; Van Deursen \& Van Diepen, 2013). Early findings highlight important linkages between digital-technology interaction, collaboration, and optimal individual and community functioning in fully online spaces. Collectively, these studies will support development of a readiness "profile tool" aligned with fully online, collaborative learning, to be used by course participants (students and facilitators) for self-development, and by institutions to guide facilitator preparation, curriculum design, digital-tools selection, and technicalsupport procedures.

Finally, FOLC's insistence on pursuing technology-enhanced, democratized learning, as an educational ideal, is being put to the test. An international working group has formed to develop a draft FOLC survey instrument to collect data on key psychological, social, cultural, and political dimensions of community learning aligned with democratic functioning. Constructs being explored include empowerment, power-distance, selfexpression, democratic deliberation, trust, and emancipative values. This operationalization of FOLC will facilitate empirical exploration of the relationship and communication dynamics undergirding specific learning communities. As such, it will begin to address the thorny question: To what extent are FOLC ideals realized in practice? Data will be gathered from learning communities within local, fully-online programs, and from learning communities emerging through pilot programs with international partners like those in post-Soviet Ukraine (Mykhailenko et al., 2016).

In the end, the expectation and hope is that FOLC, as an ideal model, will challenge and be challenged. 


\section{Conclusion}

Built on extensive praxis and a growing body of empirical inquiry at UOIT, Canada, the Fully Online Learning Community model is a community-oriented, digital-learning model guided by a strong democratic orientation, and a commitment to socially and cognitively rich, collaborative learning. It is also a timely educational response to several pressing problems and opportunities driven by the needs of learners in an increasingly digitized and globalized world.

Although originally derived from the CoI model, and sharing a collaborativeconstructivist foundation, FOLC has moved in several divergent directions. Perhaps most importantly, it subsumes the Community of Inquiry's Teaching Presence into the social and cognitive dimensions of learning as part of a broader effort to support democratized learning that (a) decreases transactional distance, (b) builds community, and (c) refuses to privilege the experiences of pedagogues in pursuit of meaningful and socially-useful knowledge. Beyond this, it recognizes a learner's digital context (and related competencies) as endogenous variables vital to the successful functioning of a fully online community.

Bodies of empirical research conducted to date have related to digital competencies, FOLC's appropriation of Problem-based Learning, collaborative learning environments, and the dynamics of SP. In addition, FOLC is grounded on collective experiences gleaned through nearly a decade of praxis. These provide a credible foundation for describing effective online learning. Indeed, at UOIT, FOLC-based learning, supported with synchronous and asynchronous digital affordances, have ably facilitated the development of close-knit learning communities while fostering constructive criticality.

Researchers and educational practitioners are invited to contact the authors to explore research partnerships and other collaborations with the international FOLC research group, with a view to exploring social-constructivist, fully online learning, and democratizing education "from below."

\section{Acknowledgements}

The authors acknowledge the contributions of fellow researchers, instructional colleagues and learners at UOIT, and professors and students from Kyiv National Economic University, Ukraine. They have contributed greatly to the ongoing theorization and empirical development of the Fully Online Learning Community model.

\section{Authors' contributions}

All the authors (TJBB, RO, WB, MDG and EC), in association with the EILAB, UOIT, Canada, made substantial

contributions to this study, and the ongoing theorization, democratization and cross-cultural exploration of the Fully

Online Learning Community (FOLC) model, authored by RO. All the authors read and approved the final manuscript.

\section{Competing interests}

The authors declare that they have no competing interests.

\section{Publisher's Note}

Springer Nature remains neutral with regard to jurisdictional claims in published maps and institutional affiliations.

\section{Author details}

${ }^{1}$ University of Ontario Institute of Technology, Oshawa, Canada. ${ }^{2}$ Royal Roads University, Victoria, Canada.

Received: 1 December 2016 Accepted: 2 March 2017

Published online: 13 April 2017

References

Allen, I. E., \& Seaman, J. (2016). Online report card: Tracking online education in the United States. Retrieved from http://onlinelearningsurvey.com/reports/onlinereportcard.pdf

Anderson, T. (2004). Towards a theory of online learning. In T. Anderson \& F. Elloumi (Eds.), Theory and practice of online learning (p. 472). Edmonton, Alberta: Athabasca University Press. 
Aparicio, M., Bacao, F., \& Oliveira, T. (2016). An e-learning theoretical framework. Journal of Educational Technology \& Society, 19(1), 292-307.

Armellini, A., \& De Stefani, M. (2015). Social presence in the 21st century: An adjustment to the Community of Inquiry framework. British Journal of Educational Technology, 47(6), 1202-1216. doi:10.1111/bjet.12302.

Atkins, S. (2013). Ambient Insight Whitepaper. The 2012 boom in learning technology investment. Retrieved from http:/www.ambientinsight.com/Resources/Documents/AmbientInsight-2012-Learning-Technology-Investment-Patterns.pdf

Beetham, H., \& Sharpe, R. (2007). Rethinking pedagogy for a digital age: Designing for 21st century learning. New York: Routledge.

Bencze, J. L. (2008). Science \& Technology Learning Cycles: Teaching and learning based on constructivist learning principles. Retrieved from http://webspace.oise.utoronto.ca/ benczela/Constructivist_SandTed.html

Bivens, F., \& Taylor, P. (2008). Learning Democracy through dialogue: Reimagining the potential of higher education institutions to support processes of positive social change. Paper presented at the Learning Democracy by Doing Alternative Practices in Citizenship Learning and Participatory Democracy Transformative Learning Centre Conference, OISE/UT, Toronto, Canada.

Chen, G., Wang, C., Yang, S., Lu, W., \& Chang, C. (2013). Digital learning playground: supporting authentic learning experiences in the classroom. Interactive Learning Environments, 21(2), 172-183. doi:10.1080/10494820.2012.705856.

Conference Board of Canada. (2016). Employability Skills 2000+. Retrieved from http:/www.conferenceboard.ca/topics/ education/learning-tools/employability-skills.aspx

Contact North. (2016). Studyonline.ca: Contact North Online Learning. Retrieved from http://studyonline.ca/

Coomey, M., \& Stephenson, J. (2001). Online learning: It is all about dialogue, involvement, support and control-according to the research. In J. Stephenson (Ed.), Teaching and learning online: Pedagogies for new technologies (pp. 37-52). London: Kogan Page.

Coppedge, M., Lindberg, S., Skaaning, S.E., \& Teorell, J. (2016). Measuring high level democratic principles using the V-Dem data. International Political Science Review, 37(5), 580-593. doi:10.1177/0192512115622046.

Dalsgaard, C., \& Paulsen, M. F. (2009). Transparency in cooperative online education. The International Review of Research in Open and Distributed Learning, 10(3), 1-13. doi:10.19173/irrodl.v10i3.671

Desjardins, F. J. \& vanOostveen, R. (2008a). Implementing PBL online as a collaborative learning strategy for teachers: The COLE. In Proceedings of The Eleventh IASTED International Conference on Computers and Advanced Technology in Education (pp. 85-89). Crete: Acta Press.

Desjardins, F. J. \& vanOostveen, R. (2008b). Collaborative Online Learning Environment: Towards a process driven approach and collective knowledge building. In Proceedings of the Ed-Media Conference on Education Multimedia, Hypermedia \& Telecommunications (pp. 2563-2570). Vienna: Association for the Advancement of Computing in Education (AACE).

Desjardins, F. J. \& vanOostveen, R. (2015). Faculty and student use of digital technology in a "laptop" university. Paper presented at the Ed-Media 2015 World Conference on Educational Media and Technology, Montreal, Quebec, Canada.

Desjardins, F. J. (2005). Information and communication technology in education: A competency profile of francophone secondary school teachers in Ontario. Canadian Journal of Learning and Technology/La revue canadienne de l'apprentissage et de la technologie, 31(1), 1-14.

Desjardins, F. J., Davidson, A.-L., Blayone, T., vanOostveen, R., \& Childs, E. (2015). General Technology Competency and Use: Foundations. Retrieved from http://eilab.ca/wp-content/uploads/2016/01/GTCU-Poster-V2-2000px.jpg

Desjardins, F. J., Lacasse, R., \& Belair, L. M. (2001). Toward a definition of four orders of competency for the use of information and communication technology (ICT) in education. Paper presented at the Computers and Advanced Technology in Education, Banff, Canada.

Dewey, J. (1897). My pedagogical creed. School Journal, 54(3), 77-80.

Dewey, J. (1933). How we think: A restatement of the relation of reflective thinking to the educative process. Boston: D.C. Heath. Edmundson, A. (Ed.). (2007). Globalized e-learning cultural challenges. Hershey: Information Science Publishing.

Eshet-Alkalai, Y., \& Amichai-Hamburger, Y. (2004). Experiments in digital literacy. CyberPsychology \& Behavior, 7(4), 421-429.

Ewert, G. D. (1991). Habermas and education: A comprehensive overview of the influence of Habermas in educational literature. Review of Educational Research, 61(3), 345-378.

Flint, N. R. A., \& Johnson, B. (2011). Towards fairer university assessment recognizing the concerns of students. New York: Routledge.

Garrison, D. R. (2011). E-learning in the 21st century: A framework for research and practice (2nd ed.). New York: Taylor \& Francis.

Garrison, D. R. (2013). Theoretical foundations and epistemological insights of the community of inquiry. In Z. Akyol \&

D. R. Garrison (Eds.), Educational communities of inquin: Theoretical framework, research and practice (pp. 1-11). Hershey: Information Science Reference.

Garrison, D. R. (2016). Thinking collaboratively: Learning in a community of inquiry. New York: Routledge.

Garrison, D. R., Anderson, T., \& Archer, W. (2000). Critical inquiry in a text-based environment: Computer conferencing in higher education. The Internet and Higher Education, 2(2), 87-105. doi:10.1016/s1096-7516(00)00016-6.

Garrison, D. R., Cleveland-Innes, M., Koole, M., \& Kappelman, J. (2006). Revisiting methodological issues in transcript analysis: Negotiated coding and reliability. The Internet and Higher Education, 9(1), 1-8. doi:10.1016/j.iheduc.2005.11.001.

Gaventa, J. (2006). Triumph, deficit or contestation? Deepening the 'Deepening Democracy' debate. IDS Working Paper in conjunction with LogoLink and the Citizenship DRC. Institute of Development Studies, University of Sussex, Brighton, UK.

Goodfellow, R., \& Lamy, M.-N. (2009). Learning cultures in online education. London: Continuum.

Grant, C. A., \& Gibson, M. L. (2013). "The path of social justice": A human rights history of social justice education. Equity \& Excellence in Education, 46(1), 81-99. doi:10.1080/10665684.2012.750190.

Gunawardena, C. N. (1995). Social presence theory and implications for interaction and collaborative learning in computer conferences. International Journal of Educational Telecommunications, 1(2/3), 147-166.

Gunawardena, C. N. (2014). Globalization, culture, and online distance learning. In O. Zawacki-Richter \& T. Anderson (Eds.), Online distance education: Towards a research agenda (pp. 75-107). Edmonton, AB: AU Press, Athabasca University.

Gunawardena, C. N., Wilson, P. L., \& Nolla, A. C. (2003). Culture and online education. In M. G. Moore \& W. G. Anderson (Eds.), Handbook of distance education (3rd ed., pp. 753-775). Mahwah: Lawrence Erlbaum Associates.

Halpern, D., \& Gibbs, J. (2013). Social media as a catalyst for online deliberation? Exploring the affordances of Facebook and YouTube for political expression. Computers in Human Behavior, 29(3), 1159-1168. doi:10.1016/j.chb.2012.10.008. 
Hellwig, W., \& Lipenkowa, J. (2007). Ukraine. In W. Horner, H. Dobert, B. von Kopp, \& W. Mitter (Eds.), The education systems of Europe (pp. 808-825). Dordrecht: Springer.

Herrington, J. \& Herrington, A. (1998). Authentic assessment and multi-media: how university students response to a model of authentic assessment. Higher Education Research \& Development, 17(3), 305-322. doi: 10:1080/0729436980170304

Herrington, J., \& Parker, J. (2013). Emerging technologies as cognitive tools for authentic learning. British Journal of Educational Technology, 44(4), 607-615. doi:10.1111/bjet.12048.

Herrington, J., Reeves, T. C., \& Oliver, R. (2006). Authentic tasks online: A synergy among learner, task, and technology. Distance Education, 27(2), 233-247. doi:10.1080/01587910600789639.

Hofstede, G. (1986). Cultural differences in teaching and learning. International Journal of Intercultural Relations, 10(3), 301-320.

Hofstede, G. (2001). Culture's consequences: Comparing values, behaviors, institutions and organizations across nations (2nd ed.). London: Sage Publications.

Hofstede, G. (2011). Dimensionalizing cultures: The Hofstede model in context. Online Readings in Psychology and Culture, 2(1), 1-26. doi:10.9707/2307-0919.1014.

Hrastinski, S. (2008). Asynchronous and synchronous e-learning. Educause Quarterly, 31(4), 51-55.

Jézégou, A. (2010). Community of Inquiry in e-learning: A critical analysis of the Garrison and Anderson model. International Journal of E-Learning \& Distance Education, 24(3), 1-12.

Johnson, M., \& Liber, O. (2008). The Personal Learning Environment and the human conditions: From theory to teaching practice. Interactive Learning Environments, 16(1), 3-15. doi:10.1080/10494820701772652.

Jones, A., \& Graham, L. (2015). Democratizing higher education learning: A case study of networked classroom research. International HETL Review, 5, 1-18.

Kearney, M., Schuck, S., Burden, K., \& Aubusson, P. (2012). Viewing mobile learning from a pedagogical perspective. Research in Learning Technology, 20, 1-17. doi:10.3402/rlt.v20i0.14406.

Knobloch, K. R., Gastil, J., Reedy, J., \& Cramer Walsh, K. (2013). Did they deliberate? Applying an evaluative model of democratic deliberation to the Oregon Citizens' Initiative Review. Journal of Applied Communication Research, 41(2), 105-125. doi:10.1080/00909882.2012.760746.

Knowles, M. S., Holton, E. F., III, et al. (2005). The adult learner. San Diego: Elsevier.

Kutsyuruba, B. (2011). Education in the period of post-Soviet transition in Ukraine. Demokratizatsiya, 19(3), 287-309.

Kutsyuruba, B., \& Kovalchuk, S. (2015). Stated or actual in policy terrain? Review of the literature on the Bologna process implementation within the context of teacher education in Ukraine. Journal of Ukrainian Politics and Society, 1(1), 33-57.

Lave, J., \& Wenger, E. (1991). Situated learning: Legitimate peripheral participation. New York: Cambridge University Press.

Layne, M., \& Ice, P. (2014). Merging the best of both worlds: Introducing Col-TLP model. In B. Sutton \& A. Basiel (Eds.), Teaching and learning online: New models of learning for a connected world (Vol. 2, pp. 3-20). New York: Routledge.

Levin, B. (2000). Putting students at the centre in education reform. Journal of Educational Change, 1(2), 155-172. doi:10.1023/A:1010024225888.

Lipman, M. (2003). Thinking in education (2nd ed.). New York: Cambridge University Press.

Löwy, I. (1990). The strength of loose concepts-boundary concepts, federative experimental strategies and disciplinary growth: The case of immunology. History of Science, 30(90), 371-396.

McCarthy, G. (2013). Authentic assessment-key to learning. In E. Doyle, P. Buckley, \& C. Carroll (Eds.), Innovative Business School Teaching-Engaging the Millennial Generation (pp. 81-92). United Kingdom: Routledge.

Mezirow, J. (1991). Transformative dimensions in adult learning. San Francisco: Jossey-Bass.

Miller, M. D. (2014). Minds online: Teaching effectively with technology. Cambridge, Massachusetts: Harvard University Press.

Minkov, M. (2012). Cross-cultural analysis: The science and art of comparing the world's modern societies and their cultures. Thousand Oaks: Sage Publications.

Moore, M. G. (1993). Theory of transactional distance. In D. Keegan (Ed.), Theoretical principles of distance education. New York: Routledge.

Morgan, T. (2011). Online classroom or community-in-the-making? Instructor conceptualizations and teaching presence in international online contexts. Journal of Distance Education (Online), 25(1), 1-14.

Mykhailenko, O., Blayone, T., \& VanOostveen, R. (2016). Exploring democratized learning and dimensions of culture for educational transformation in Ukraine. Paper presented at the RIDRU Conference Higher Education Reforms in Post-Maidan Ukraine, Alberta, Canada.

Noldus Information Technology. (2016). Noldus: Innovative solutions for behavioural research. Retrieved from http://www.noldus.com

Palalas, A., Berezin, N., Gunawardena, C., \& Kramer, G. (2015). A design based research framework for implementing a transnational mobile and blended learning solution. International Journal of Mobile and Blended Learning, 7(4), 57-74. doi:10.4018/JMBL.2015100104.

Parris, D. L., \& Peachey, J. W. (2013). A systematic literature review of servant leadership theory in organizational contexts. Journal of Business Ethics, 113(3), 377-393. doi:10.1007/s10551-012-1322-6.

Paulsen, M. F. (2008). Cooperative online education. Seminar.net: International Journal of Media, Technology and Lifelong Learning, $N(N), 4(2), 1-20$.

Paulsen, M. F. (2003). Online education and learning management systems-Global e-learning in a Scandinavian perspective. Bekkestua: NKI Forlaget.

Popper, K. R. (1978). Three worlds. Paper presented at the The Tanner Lecture on Human Values, The University of Michigan, Ann Arbor. http://tannerlectures.utah.edu/_documents/a-to-z/p/popper80.pdf.

Richardson, J. C., Arbaugh, J. B., Cleveland-Innes, M., Ice, P., Swan, K. P., \& Garrison, D. R. (2012). Using the community of inquiry framework to inform effective instructional design. In L. Moller \& J. B. Huett (Eds.), The next generation of distance education: Unconstrained learning (pp. 97-125). New York: Springer.

Rockinson-Szapkiw, A., \& Wendt, J. (2015). Technologies that assist in online group work: A comparison of synchronous and asynchronous computer mediated communication technologies on students' learning and community. Journal of Educational Multimedia and Hypermedia, 24(3), 263-279.

Rourke, L., \& Anderson, T. (2004). Validity in quantitative content analysis. Educational Technology Research and Development, 52(1), 5-18. doi:10.1007/bf02504769. 
Rourke, L., Anderson, T., Garrison, D. R., \& Archer, W. (1999). Assessing social presence in asynchronous text-based computer conferencing. Journal of Distance Education, 14(2), 50-71.

Rourke, L., Anderson, T., Garrison, D. R., \& Archer, W. (2001). Methodological issues in the content analysis of computer conference transcripts. International Journal of Artificial Intelligence in Education, 12, 8-22.

Rovai, A. P. (2002a). Building sense of community at a distance. The International Review of Research in Open and Distributed Learning, 3(1), 1-16. doi:10.19173/irrodl.v3i1.79

Rovai, A. P. (2002a). Sense of community, perceived cognitive learning, and persistence in asynchronous learning networks. The Internet and Higher Education, 5(4), 319-332. doi:10.1016/s1096-7516(02)00130-6.

Rubin, B. C. (2007). "Laboratories of democracy": A situated perspective on learning social studies in detracked classrooms. Theory \& Research in Social Education, 35(1), 62-95. doi:10.1080/00933104.2007.10473326.

Savin-Baden, M. (2000). Problem-Based Learning in higher education: Untold stories. Philadelphia, PA: Open University Press.

Savin-Baden, M. (2007). Challenging models and perspectives of problem-based learning. In E. De Graaff \& A. Kolmos (Eds.), Management of change: Implementation of problem-based and project-based learning in engineering (pp. 9-30). Rotterdam: Sense Publishing.

Siemens, G., Gašević, D., \& Dawson, S. (2015). Preparing for the digital university: A review of the history and current state of distance, blended, and online learning. Retrieved from http://linkresearchlab.org/PreparingDigitalUniversity.pdf

Taylor, E. W. (2007). An update of transformative learning theory: A critical review of the empirical research (1999-2005). International Journal of Lifelong Education, 26(2), 173-191. doi:10.1080/02601370701219475.

Taylor, E. W. (2008). Transformative learning theory. New Directions for Adult and Continuing Education, 2008(119), 5-15. doi:10.1002/ace.301.

Taylor, E. W. (2016). Teacher transformation: a transformative learning perspective. Italian Journal of Educational Research, 15, 17-26.

Tibbitts, F. (2005). Transformative learning and human rights education: Taking a closer look. Intercultural Education, 16(2), 107-113. doi:10.1080/14675980500133465.

Tibbitts, F., \& Kirchschlaeger, P. G. (2010). Perspectives of research on human rights education. Journal of Human Rights Education, 2(1), 8-29.

Trevino, L. K., Lengel, R. H., \& Daft, R. L. (1987). Media symbolism, media richness, and media choice in organizations a symbolic interactionist perspective. Communication Research, 14(5), 553-574. doi:10.1177/009365087014005006.

Van Deursen, A. J. A. M., \& Van Diepen, S. (2013). Information and strategic Internet skills of secondary students: A performance test. Computers \& Education, 63, 218-226. doi:10.1016/j.compedu.2012.12.007.

vanOostveen, R., Muirhead, W., \& Goodman, W. (2011). Tablet PCs and reconceptualizing learning with technology. Interactive Technology and Smart Education, 8(2), 78-93. doi:10.1108/17415651111141803.

vanOostveen, R., Desjardins, F., Bullock, S., DiGiuseppe, M. \& Robertson, L. (2010). Towards a reconceptualization of online teacher professional learning: Problem-based learning objects (PBLOs). In Proceedings of the Ed-Media Conference on Education Multimedia, Hypermedia \& Telecommunications. Toronto, ON.

vanOostveen, R., DiGiuseppe, M., Barber, W., Blayone, T., \& Childs, E. (2016). New conceptions for digital technology sandboxes: Developing a Fully Online Learning Communities (FOLC) model. Paper presented at EdMedia 2016 World Conference on Educational Media and Technology, Vancouver, B.C., Canada.

vanOostveen, R., Childs, E., Clarkson, J. \& Flynn, K. (2015). Becoming close with others online: Distributed community building in online PBL courses. Paper presented at EdMedia 2015 World Conference on Educational Media and Technology, Montreal, Quebec, Canada.

Veletsianos, G. (2016). Digital learning environments. In N. Rushby \& D. Surry (Eds.), Wiley Handbook of Learning Technology (p. 242). Oxford: Wiley.

Voogt, J., \& Roblin, N. P. (2012). A comparative analysis of international frameworks for 21st century competences: Implications for national curriculum policies. Journal of Curriculum Studies, 44(3), 299-321. doi:10.1080/00220272. 2012.668938.

Wenger, E. (1998). Communities of practice: Learning as a social system. Systems Thinker, 9(5), 2-3.

Wenger, E. C., \& Snyder, W. M. (2000). Communities of practice: The organizational frontier. Harvard Business Review, 78(1), 139-146.

World Economic Forum. (2016). The 10 skills you need to thrive in the Fourth Industrial Revolution. Retrieved from http://www.weforum.org/agenda/2016/01/the-10-skills-you-need-to-thrive-in-the-fourth-industrial-revolution

Yoo, B., Donthu, N., \& Lenartowicz, T. (2011). Measuring Hofstede's five dimensions of cultural values at the individual level: Development and validation of CVSCALE. Journal of International Consumer Marketing, 23(3-4), 193-210. doi:10.1080/08961530.2011.578059.

\section{Submit your manuscript to a SpringerOpen ${ }^{\circ}$ journal and benefit from:}

- Convenient online submission

- Rigorous peer review

- Immediate publication on acceptance

- Open access: articles freely available online

- High visibility within the field

- Retaining the copyright to your article

Submit your next manuscript at $\gg$ springeropen.com 